\title{
Determination of size-independent specific fracture energy of concrete from three-point bend and wedge splitting tests
}

\author{
H. M. Abdalla* and B. L. Karihaloo* \\ Cardiff University
}

Three-point bend (TPB) and wedge splitting (WS) tests have been conducted on three different concretes and the specific fracture energy $G_{F}$ determined on the basis of the concept of local fracture energy. The latter is influenced by the free back surface of a notched test specimen, as explained by Hu and Wittmann. Tests on three or four specimen sizes with four notch to depth ratios confirm the idea of Hu and Wittmann that the size-independent specific fracture energy $G_{F}$ can be determined from measured fracture energy values that vary with the size of the specimen, $W$, and notch to depth ratio, a/W. More importantly, it is shown that the same size-independent $G_{F}$ can also be obtained by testing a single size specimen with only two notch to depth ratios, provided they are well separated $(a / W=0.05$ and 0.50 in $T P B$, and 0.2 and 0.5 in WS), thus greatly simplifying the determination of the size-dependent fracture energy $\mathrm{G}_{F}$.

\section{Introduction}

The specific fracture energy $G_{F}$ is the most useful material parameter in the analysis of cracked concrete structures. ${ }^{1}$ The method of experimental determination of the fracture energy, $G_{F}$, and even its definition has been a subject of debate among researchers because of its variability with the size and shape of the test specimen. Guinea et al. ${ }^{2}$ identified several sources of energy dissipation that may influence the measurement of $G_{F}$, for example the influence of curtailing the $P-\delta$ tail in a bend test. ${ }^{3}$ They concluded that when all these sources are taken into account an almost size-independent specific fracture energy $G_{F}$ can be obtained. $\mathrm{Hu}$ and Wittmann ${ }^{4}$ have addressed the possibility that the specific fracture energy itself may not be constant along the crack path in a test specimen.

\footnotetext{
* Division of Civil Engineering, Cardiff University, Queen's Buildings, Cardiff CF24 OYF, UK.
}

(MCR 1027) Paper received 14 March 2002; last revised 5 June 2002; accepted 8 August 2002
The recent model of Duan et al. ${ }^{5}$ assumes that the fracture energy required to create a crack along the crack path is influenced by the size of the fracture process zone (FPZ) which in turn is influenced by the free boundary of the test specimen. To consider the boundary effect on the propagation of FPZ, they assumed a bilinear fracture energy distribution to explain the ligament effect on the fracture energy of concrete. When this effect is included, they obtain a size-independent fracture energy, which is needed for an accurate estimate of the load bearing capacity of cracked concrete structures. This is because only in this way can the spurious size dependency introduced by the size dependency of the fracture energy itself be avoided.

The influence of curtailing the tail part of the loaddeflection $(P-\delta)$ diagram in a bend test studied by Elices et al. $^{3}$ in fact gives an estimate of the energy dissipation when the load tends to zero i.e. the crack approaches the free surface of the test specimen. This is in principle similar to the boundary effect proposed by Duan et al. ${ }^{5}$ which will be further explored below.

In this paper, using the concept of 'boundary effect' and 'local fracture energy distribution', the boundary effect model of Duan et al. ${ }^{5}$ is subjected to additional verification using three-point bend (TPB) and wedge 
splitting (WS) tests on normal (NC) and high-strength (HSC) concretes. It will be shown that the boundary effect model does indeed lead to the determination of specific fracture energy that is independent of the specimen size and geometry. More importantly, it will be shown that the same size-independent specific fracture energy value can be obtained by testing just two specimens of the same size which however contain a shallow and deep starter notch, respectively.

\section{Background}

The specific fracture energy $G_{F}$ according to the RILEM recommendation ${ }^{6}$ is the average energy given by dividing the total work of fracture by the projected fracture area (i.e. the area of the initially uncracked ligament). Therefore, for a specimen of depth $W$ and initial crack (or notch) length $a$, the fracture energy is given by

$$
G_{F}=\frac{1}{(W-a) B} \int P d \delta
$$

where $B$ is the specimen thickness; $P$ is the applied load; and $\delta$ is the displacement of the load point. The weight of the specimen can be taken into account, if necessary (i.e. large specimens).

If a fictitious $\mathrm{crack}^{7,8}$ is used to model the concrete fracture, the energy dissipation for crack propagation can be completely characterised by a cohesive stress separation curve $\sigma(w)$. The area under this curve is the specific fracture energy, $G_{F}$

$$
G_{F}=\int_{0}^{w_{c}} \sigma(w) d w
$$

where $w_{\mathrm{c}}$ is the critical crack opening.

Let us examine the region ahead of a pre-existing notch, as shown in Fig. 1. The fracture process zone

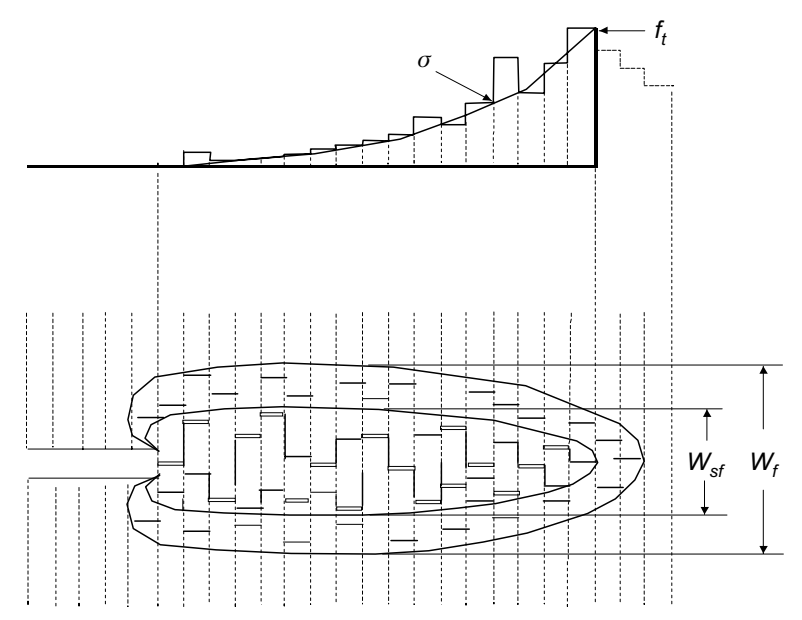

Fig. 1. The FPZ and discrete bridging stresses. The FPZ is divided into the inner softening zone and the outer microfracture zone. $w_{c}$ is related to the width of the inner softening zone $w_{s f}{ }^{1}$
(FPZ) around the propagating crack can be considered as consisting of two regions, an inner softening zone, $w_{s f}$, and an outer micro-fracture zone, $w_{f}{ }^{1,9}$ The inner softening zone $w_{s f}$ contains interconnected cracks along the aggregate and mortar interfaces. The main open crack plus a few large crack branches along the interfaces can be formed within the softening zone. The formation and complete separation of the softening zone controls the $\sigma(w)$ relationship. The outer microfracture zone contains isolated micro-cracks that are not interconnected. These do not contribute to the concrete softening but to its non-linear response before the peak load. The fracture energy consumed in the outer micro-fracture zone is small, and equations (1) and (2) should in principle determine the same specific fracture energy.

However, during crack propagation the inner and the outer zone widths $w_{s f}$ and $w_{f}$ may vary according to the crack tip stress field. Obviously the critical crack opening $w_{c}$ is limited by the inner and the outer zone widths. This limit becomes more obvious when a FPZ approaches the free boundary of a specimen. Therefore, a smaller $w_{c}$ and a smaller fracture energy are found if one uses equation (2). These variations in $w_{s f}, w_{f}$ and $w_{c}$ lead to the conclusion that the fracture energy $G_{F}$ defined by equation (2) can be dependent on the location of FPZ in relation to the free boundary of the specimen. To distinguish the fracture energy $G_{F}$ defined by equation (1) from that defined by equation (2), Duan et al..$^{5}$ use the symbol $g_{f}$ for the local fracture energy defined by equation (2).

Let $x$ denote a position along a fracture ligament in the FPZ and $g_{f}(x)$ the local fracture energy. Hu, and $\mathrm{Hu}$ and Wittmann ${ }^{4}$ have made the following assumptions

$$
\begin{gathered}
w_{s f}(x) \propto w_{f}(x) \\
w_{c}(x) \propto w_{s f}(x) \\
g_{f}(x) \propto w_{c}(x)
\end{gathered}
$$

The fracture energy defined by equation (1) which may be size- or ligament-dependent is denoted by $G_{f}(a)$, to differentiate it from the size-independent $G_{F}$.

According to the energy conservation principle, the specific fracture energy $G_{f}(a)$ defined by equation (1) can be determined as follows

$$
G_{f}(a)=\frac{1}{(W-a)} \int_{0}^{W-a} g_{f}(x) d x
$$

Differentiating equation (4) with respect to the crack length gives the local fracture energy $g_{f}(x)$ at the crack tip

$$
g_{f}(x)=G_{f}(a)-(W-a) \frac{d G_{f}(a)}{d a} .
$$

Equations (4) and (5) above imply that $G_{f}(a)=$ constant $=G_{F}$, if $g_{f}(x)=$ constant. If $g_{f}(x) \neq$ con- 
stant, $G_{f}(a) \neq$ constant, i.e. size or ligament effects are observed. Fig. 2 shows schematically that if $g_{f}(x)$ decreases when approaching the boundary of the specimen at later stages of fracture, $G_{f}(x)$ is indeed dependent on the ligament or initial crack length.

\section{Specimen size effect on fracture energy}

To simplify the previous local fracture energy analysis, $g_{f}(x)$ is assumed ${ }^{4,9}$ to vary in a bilinear manner, as shown in Fig. 3. Fig. 3(a) displays a specimen of depth $W$ and an initial crack of size $a$. The bilinear function consists of a horizontal line with the value of $G_{F}$ and a descending branch that reduces to zero at the back surface of the specimen. The intersection of these two

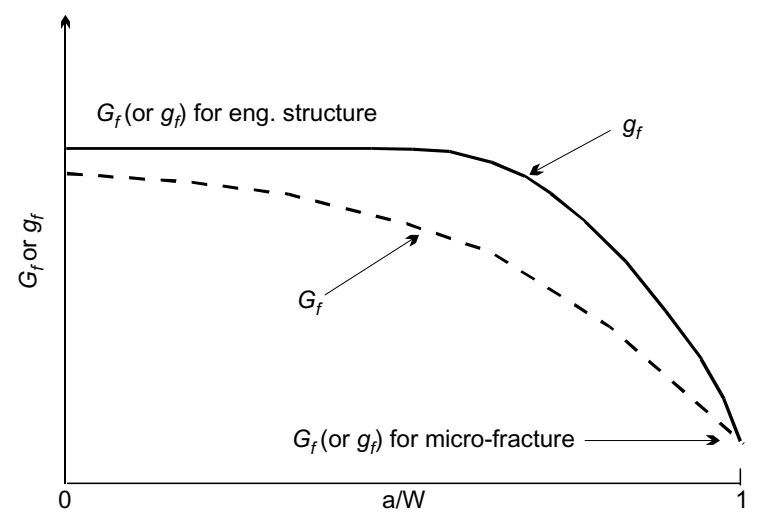

Fig. 2. If $g_{f}$ decreases monotonically along the ligament, $G_{f}$ has to be dependent on the $a / W$ ratio, as observed in many experiments.

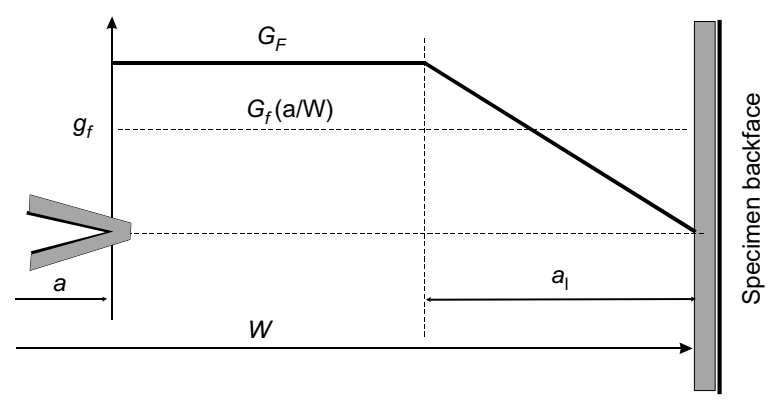

(a)

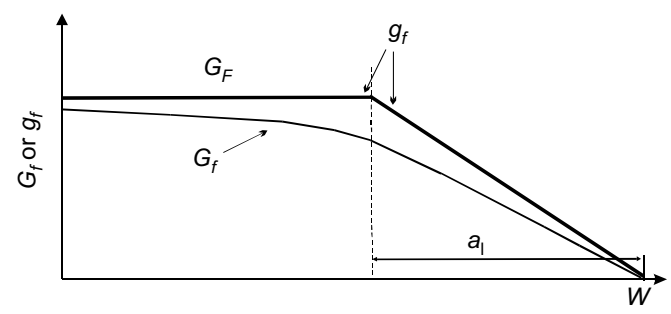

(b)

Fig. 3. The distribution of fracture energy $\left(G_{f}\right.$ and $\left.g_{f}\right)$ along the un-notched ligament of a notched test specimen of depth $W$ and notch depth $a^{5}$ straight lines is defined as the transition ligament size $a_{l}$ or the crack reference length. ${ }^{10}$ The transition ligament size $a_{l}$ is a parameter depending on both the material properties and specimen geometry.

For a specimen with a ligament size $(W-a)$ larger than the transition ligament size $a_{l}, g_{f}(x)$ is given by ${ }^{10}$

$g_{f}(x)= \begin{cases}G_{F} & x<W-a-a_{l} \\ G_{F}\left[1-\frac{x-\left(W-a-a_{l}\right)}{a_{l}}\right] & x \geqslant W-a-a_{l}\end{cases}$

If $(W-a)$ is smaller than the ligament transition length $a_{l}$, the first function in equation (6) disappears. Substituting equation (6) into equation (4) and introducing the $a / W$ ratio, $G_{F}$ is obtained

$G_{f}\left(\frac{a}{W}\right)= \begin{cases}G_{F}\left[1-\frac{1}{2} \cdot \frac{a_{l} / W}{1-a / W}\right] & 1-a / W>a_{l} / W \\ G_{F} \cdot \frac{1}{2} \cdot \frac{(1-a / W)}{a_{l} / W} & 1-a / W \leqslant a_{l} / W\end{cases}$

As shown in Fig. 3, when the initial crack length grows from $a$ to $W$, the $G_{f}(a)$ or $G_{f}(a / W)$ curve is obtained, showing the ligament effect on the fracture energy. The upper limit of $G_{f}(a / W)$ is the size-independent fracture energy $G_{F}$. It can also be seen from Fig. 3 that it is not necessary to test a very large concrete specimen, because $G_{F}$ can be back calculated from the sizedependent fracture energy $G_{f}(a / W)$, as long as $(W-a)>a_{l}$.

\section{Experimental procedure}

The tests described in this paper to confirm the boundary effect model were conducted on normal and high-strength concretes. Two different testing methods were adopted for this study, namely the three-point bend (TPB) test and the wedge splitting (WS) test.

\section{Three-point bend (TPB) test}

Fifty-six notched beams of different depths (100, 200, 300 and $400 \mathrm{~mm}$ ) with a constant span to depth ratio of 4, as shown in Fig. 4, were tested in three-point bending. Ready mix normal strength concrete (55 MPa) was used for these beams in view of the large volume of concrete needed. The notch to depth ratios were selected to be $0 \cdot 05,0 \cdot 10,0 \cdot 30$ and $0 \cdot 50$. The notch was introduced with a diamond saw. Four beams were tested for each notch to depth ratio. The testing was carried out using a Dartec closed-loop testing machine $(250 \mathrm{kN})$, capable of testing large beams.

\section{Wedge splitting (WS) test}

Wedge splitting tests were carried out on normal and high-strength concretes. These concretes were mixed in the laboratory since only small amounts of concrete 


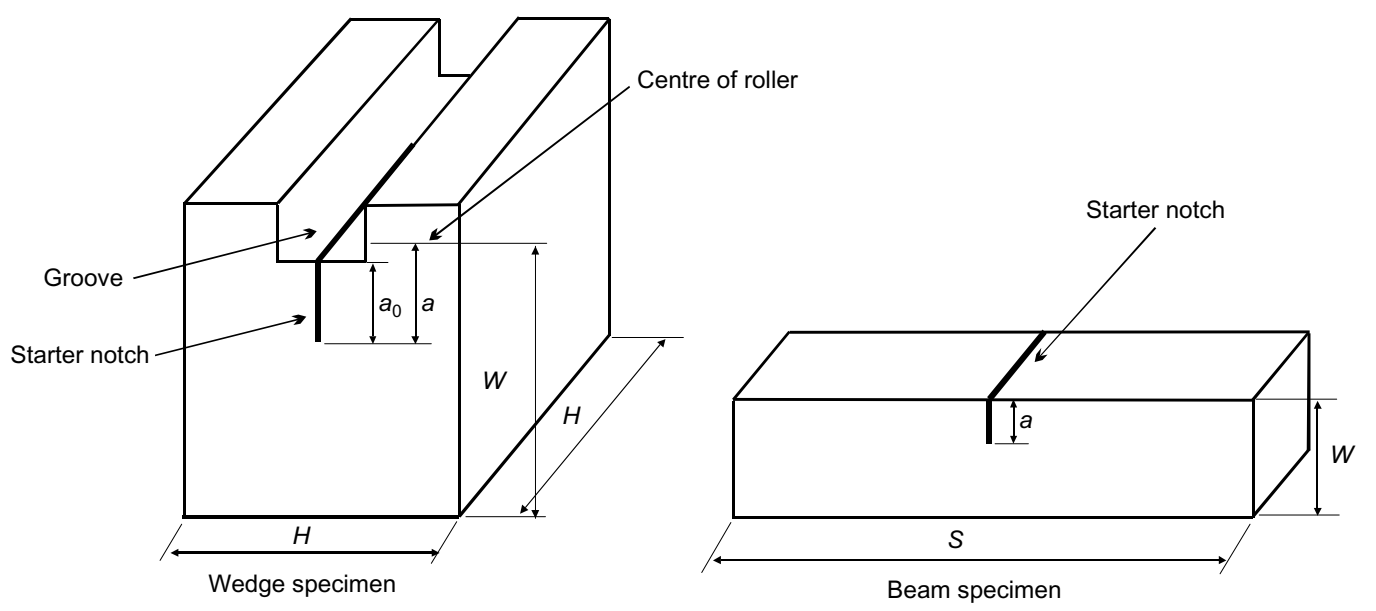

(a)

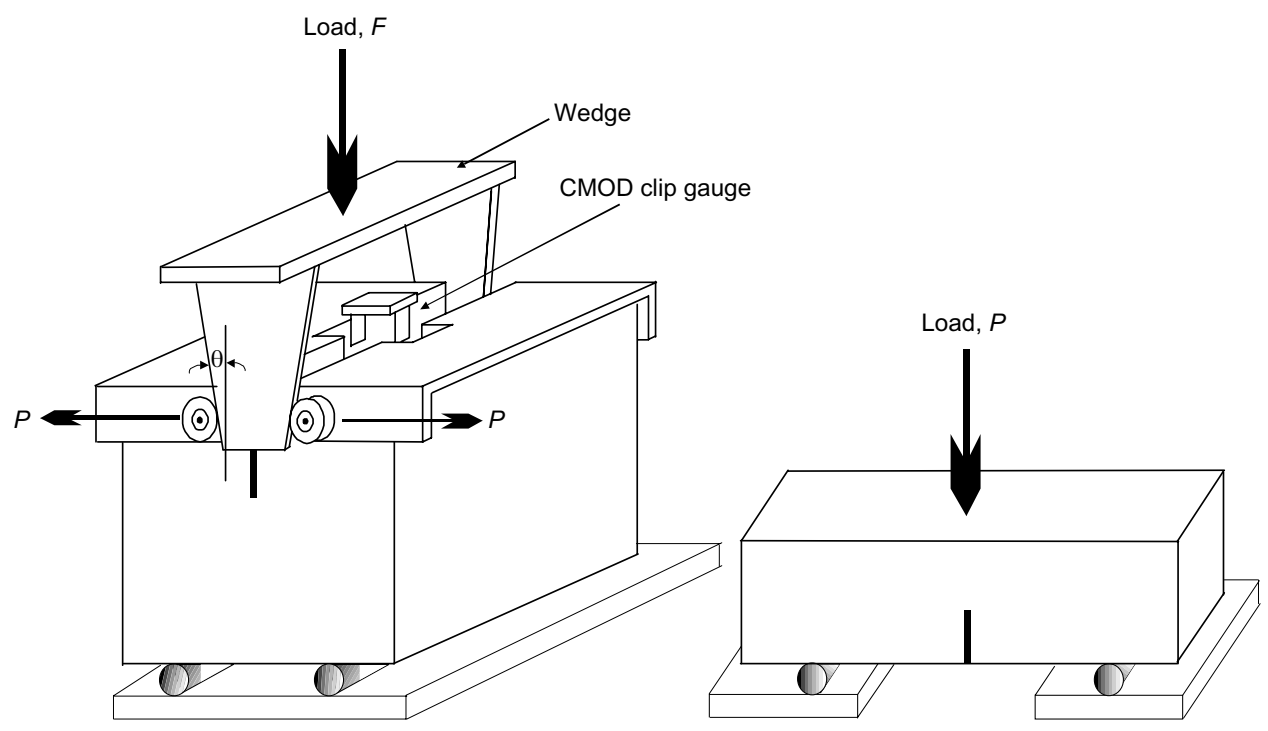

(b)

Fig. 4. (a) Specimen shapes and dimensions; (b) loading arrangements

were needed. Their compressive strengths were 60 and $100 \mathrm{MPa}$, respectively. Ninety-six test specimens of different sizes (100, 200 and $300 \mathrm{~mm}$ ), as shown in Fig. 4 were tested. The notch to depth ratios $a / W$ ranged from 0.2 to 0.5 (for the definition of notch size and depth, see Fig. 4(a)). The testing was carried out using a Dartec closed-loop testing machine $(200 \mathrm{kN})$. The rate of loading was controlled by a crack mouth opening displacement (CMOD) gauge at a very low rate $(0.0002 \mathrm{~mm} / \mathrm{s})$ so that the fracture occurred in a stable manner. The loading arrangements for TPB and WS tests are shown in Fig. 4(b). Further details of TPB and WS tests can be found in Karihaloo. ${ }^{1}$

Typical recorded load-displacement (TPB) and loadCMOD (WS) diagrams are shown in Fig. 5 from which the fracture energy $G_{f}(\alpha)(\alpha=a / W)$ was calculated using equation (1). Note that for WS specimens, the displacement $\delta$ in equation (1) is replaced with CMOD and $P$ with

$$
P=\frac{F}{2 \tan \theta}
$$

where $F$ is the vertical force on the bearings (assuming the frictional contribution to be negligible) and $\theta$ is one-half of the wedge angle (Fig. 4(b)).

The half wedge angle for the WS set up used in this study varied slightly with the size of the specimen. For specimen size $100 \mathrm{~mm} \theta=14.5^{\circ}$, for $200 \mathrm{~mm}$ it was $\theta=15^{\circ}$, and for $300 \mathrm{~mm}$ it was $\theta=15.5^{\circ}$.

\section{Analysis of experimental results}

The mean value and the coefficient of variation (COV) of the measured fracture energy $G_{f}(\alpha)$ using

Magazine of Concrete Research, 2003, 55, No. 2 


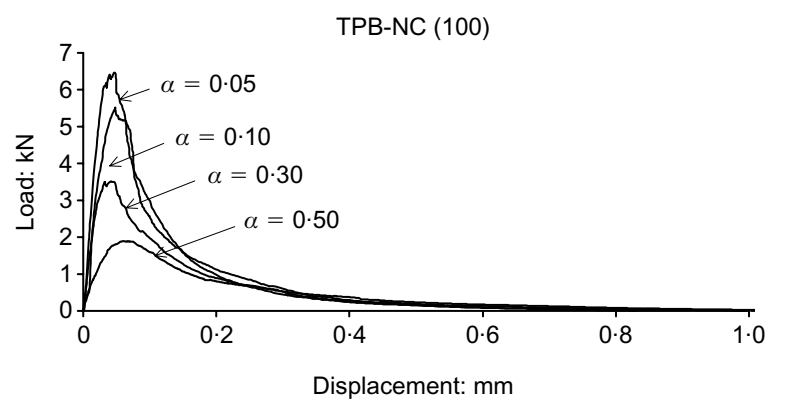

(a)

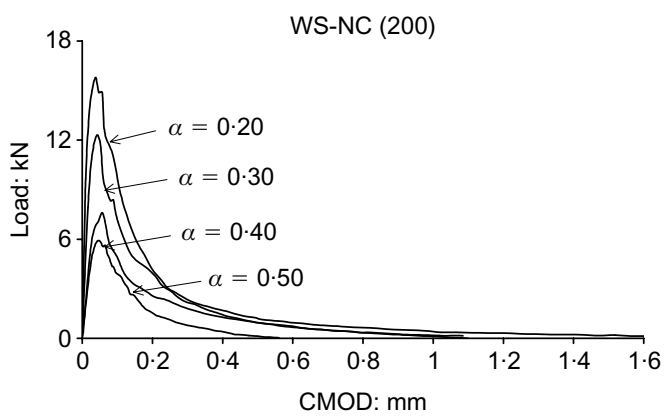

(b)

Fig. 5. Typical recorded load-displacement diagram in: (a) TPB test; (b) load-CMOD diagram in WS test

TPB and WS specimens are presented in Tables 1 and 2.

Fracture energy results from TPB tests

The test results for $G_{f}(\alpha)$ from the TPB tests were substituted into equation ( 7 ) in order to determine the size-independent fracture energy $G_{F}$ and transition ligament length $a_{l}$. As the number of results of $G_{f}(\alpha)$ for each depth $W$ and notch to depth ratio $\alpha$ was 4 , but the number of unknowns was only 2 , namely $G_{F}$ and $a_{l}$, the system of four equations was solved by a least squares method to get the best estimate of $G_{F}$ and $a_{l}$. These are listed in Table 3.

The predictions based on the parameters in Table 3 are plotted in Fig. 6; these show a good agreement with the experimental data. Fig. 6 also indicates that these curves will tend to zero when approaching the back face of the specimen, and to the $G_{F}$ value when the crack size becomes small (small notch to depth ratio). The same trend was also obtained by Duan et al. ${ }^{5}$ who used the TPB results of Nallathambi et al. ${ }^{11,12}$

Figure 7 shows the variation of the specific fracture energy $G_{f}(\alpha)$ with the specimen depth $W$ for different notch to depth ratios. Again, there is good agreement between the measured fracture energy and the prediction of the model using the parameters in Table 3 .

Figure 8 and Table 4 indicate that the specific fracture energy $G_{F}$ calculated by equation (7) remains constant independent of the specimen size. Fig. 9 indicates that the transition ligament size $a_{l}$ varies with the specimen size; it increases as the specimen size increases, but the rate of increase slows gradually.

Table 3. Estimated specific fracture energy $G_{F}$ and ligament transition length $a_{l}$ for $N C$ using $T P B$

\begin{tabular}{l|c|l|l|l}
\hline$W: \mathrm{mm}$ & 100 & 200 & 300 & 400 \\
$G_{F}: \mathrm{N} / \mathrm{m}$ & 140 & $144 \cdot 5$ & 137 & 143 \\
$a_{l}: \mathrm{mm}$ & $53 \cdot 7$ & 104 & 117 & $148 \cdot 8$ \\
\hline
\end{tabular}

Table 1. Measured fracture energy, $G_{f}(\alpha)$ for NC from three-point bend test

\begin{tabular}{|c|c|c|c|c|c|c|c|c|c|}
\hline & \multirow{2}{*}{$\begin{array}{l}\mathrm{W}: \mathrm{mm} \\
\alpha: a / W\end{array}$} & \multicolumn{2}{|c|}{100} & \multicolumn{2}{|c|}{200} & \multicolumn{2}{|c|}{300} & \multicolumn{2}{|c|}{400} \\
\hline & & $G_{f}(\alpha): \mathrm{N} / \mathrm{m}$ & $\mathrm{COV}$ & $G_{f}(\alpha): \mathrm{N} / \mathrm{m}$ & $\mathrm{COV}$ & $G_{f}(\alpha): \mathrm{N} / \mathrm{m}$ & $\mathrm{COV}$ & $G_{f}(\alpha): \mathrm{N} / \mathrm{m}$ & $\mathrm{COV}$ \\
\hline $\mathrm{NC}$ & $\begin{array}{l}0 \cdot 05 \\
0 \cdot 1 \\
0 \cdot 3 \\
0 \cdot 5\end{array}$ & $\begin{array}{l}101 \\
88 \cdot 8 \\
82 \cdot 0 \\
65 \cdot 2\end{array}$ & $\begin{array}{r}0 \cdot 7 \% \\
20 \cdot 2 \% \\
6 \cdot 4 \% \\
5 \cdot 2 \%\end{array}$ & $\begin{array}{r}104 \cdot 8 \\
96 \cdot 6 \\
85 \cdot 8 \\
69 \cdot 0\end{array}$ & $\begin{array}{r}3 \cdot 4 \% \\
21 \cdot 5 \% \\
8 \cdot 9 \% \\
6 \cdot 3 \%\end{array}$ & $\begin{array}{c}110 \\
101 \\
98 \cdot 9\end{array}$ & $\begin{array}{r}6 \cdot 4 \% \\
12 \cdot 7 \% \\
4 \cdot 6 \%\end{array}$ & $\begin{array}{l}116 \\
109 \\
104\end{array}$ & $\begin{array}{l}2 \cdot 5 \% \\
10 \% \\
13 \cdot 2 \%\end{array}$ \\
\hline
\end{tabular}

Table 2. Measured fracture energy, $G_{f}(\alpha)$ for NC and HSC from wedge splitting test

\begin{tabular}{|c|c|c|c|c|c|c|c|}
\hline & \multirow{2}{*}{$\begin{array}{l}\text { W: mm } \\
\alpha: a / W\end{array}$} & \multicolumn{2}{|c|}{100} & \multicolumn{2}{|c|}{200} & \multicolumn{2}{|c|}{300} \\
\hline & & $G_{f}(\alpha): \mathrm{N} / \mathrm{m}$ & $\mathrm{COV}$ & $G_{f}(\alpha): \mathrm{N} / \mathrm{m}$ & $\mathrm{COV}$ & $G_{f}(\alpha): \mathrm{N} / \mathrm{m}$ & $\mathrm{COV}$ \\
\hline \multirow{4}{*}{$\mathrm{NC}$} & $0 \cdot 2$ & $77 \cdot 6$ & $4 \cdot 2 \%$ & $89 \cdot 4$ & $7 \cdot 1 \%$ & 103 & $4 \cdot 3 \%$ \\
\hline & $0 \cdot 3$ & $52 \cdot 3$ & $15.9 \%$ & $78 \cdot 1$ & $15 \cdot 1 \%$ & $85 \cdot 5$ & $6 \cdot 0 \%$ \\
\hline & $0 \cdot 4$ & $41 \cdot 4$ & $3 \cdot 8 \%$ & $68 \cdot 0$ & $6 \cdot 2 \%$ & $84 \cdot 2$ & $16.5 \%$ \\
\hline & 0.5 & $32 \cdot 4$ & $13 \cdot 5 \%$ & $41 \cdot 2$ & $8 \cdot 5 \%$ & $62 \cdot 1$ & $13 \cdot 8 \%$ \\
\hline & $0 \cdot 2$ & $67 \cdot 5$ & $11.9 \%$ & $73 \cdot 1$ & $11 \cdot 5 \%$ & $75 \cdot 0$ & $10 \cdot 7 \%$ \\
\hline \multirow[t]{3}{*}{ HSC } & $0 \cdot 3$ & $56 \cdot 7$ & $12 \cdot 7 \%$ & $63 \cdot 1$ & $3 \cdot 8 \%$ & $65 \cdot 6$ & $11.5 \%$ \\
\hline & $0 \cdot 4$ & $42 \cdot 4$ & $17 \cdot 4 \%$ & $49 \cdot 6$ & $10 \cdot 0 \%$ & $52 \cdot 0$ & $6.9 \%$ \\
\hline & 0.5 & $32 \cdot 9$ & $14 \cdot 4 \%$ & $43 \cdot 8$ & $5 \cdot 6 \%$ & $46 \cdot 3$ & $4 \cdot 1 \%$ \\
\hline
\end{tabular}




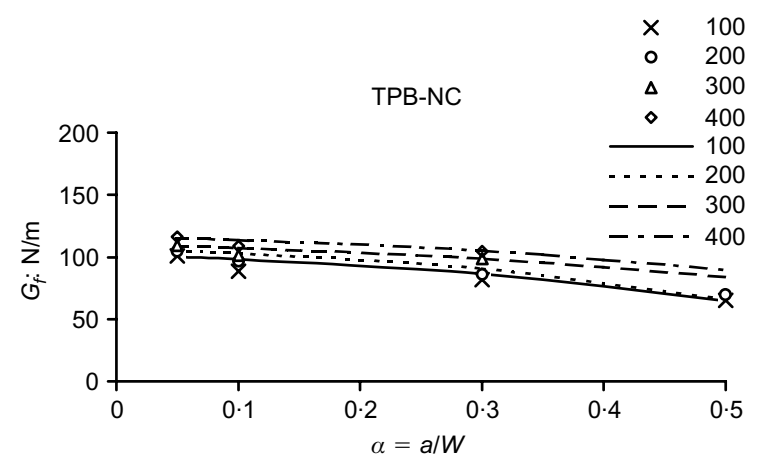

Fig. 6. Comparison of the TPB test data for different notch to depth ratios with equation (7)

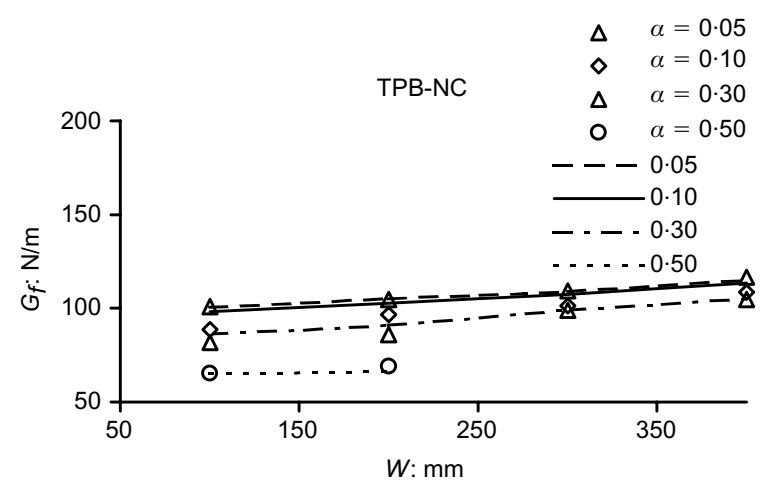

Fig. 7. Comparison of the TPB test data for different specimen depths $W$ with equation (7). Note that only two depths were tested with $\alpha=0.50$

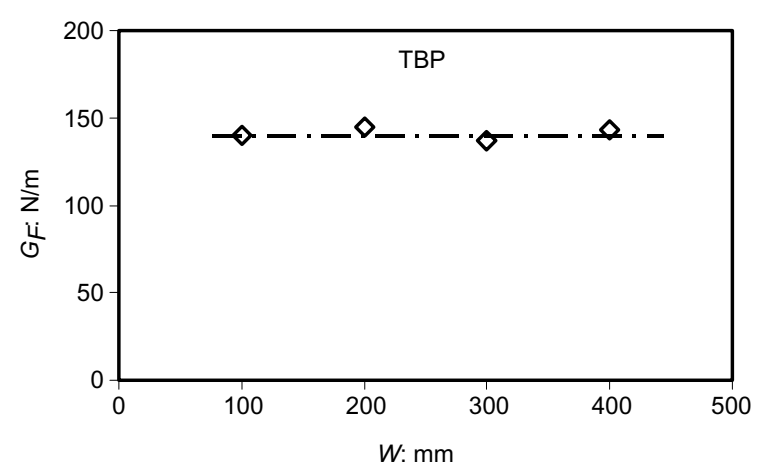

Fig. 8. The size-independent fracture energy $G_{F}$ as a function of $W$, predicted by equation (7)

Table 4. Estimated specific fracture energy $G_{F}$ and ligament transition length $a_{l}$ for NC using WS test

\begin{tabular}{l|c|l|l}
\hline$W:(\mathrm{mm})$ & 100 & 200 & 300 \\
$G_{F}: \mathrm{N} / \mathrm{m}$ & 153 & 155 & $156 \cdot 3$ \\
$a_{l}: \mathrm{mm}$ & $78 \cdot 8$ & $135 \cdot 6$ & 166 \\
\hline
\end{tabular}

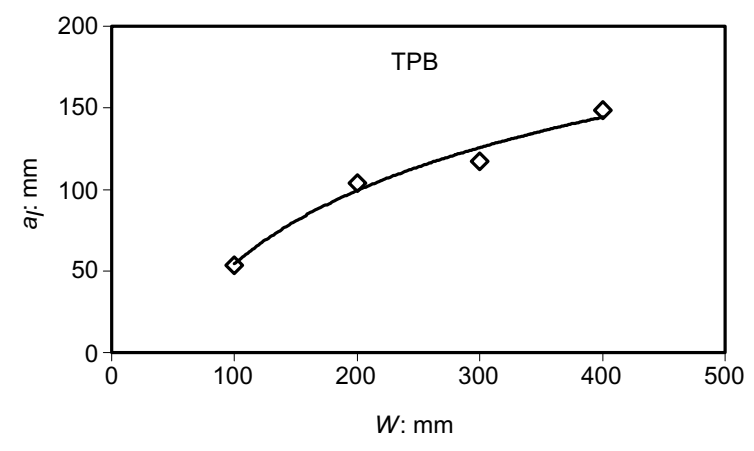

Fig. 9. The transition ligament $a_{l}$ as a function of $W$, predicted by equation (7)

\section{Fracture energy results from WS tests}

The results of the specific fracture energy $G_{F}$ and the transition ligament length $a_{l}$ for $\mathrm{NC}$ calculated using equation (7) and a least squares method are shown in Table 4 . Note that this NC (60 MPa) made in the laboratory is somewhat stronger than the ready mix $\mathrm{NC}(55 \mathrm{MPa})$ tested in TPB, so that the $G_{F}$ is also somewhat higher. The predictions using the specific fracture energy and the ligament transition length $a_{l}$ shown in Table 4 are plotted in Fig. 10 to compare the measured fracture energy $G_{f}(\alpha)$ with equation (7). The agreement is very satisfactory. The model gives the correct trend, i.e. the fracture energy tends to zero when the notch tip approaches the back surface of the test specimen. Fig. 11 shows the variation of the fracture energy $G_{f}(\alpha)$ with the specimen depth $W$ for the different notch to depth ratios studied here. Fig. 11 also shows good agreement of the measured fracture energy $G_{f}(\alpha)$ using the specific fracture energy $G_{F}$ and the ligament transition length $a_{l}$ of Table 4 .

Figure 12 and Table 4 again show that the specific fracture energy $G_{F}$ remains constant independently of the specimen size for NC. As before, the transition ligament size increases with specimen size but tends towards a plateau at large sizes (see Fig. 13).

The results of the specific fracture energy $G_{F}$ and the transition ligament length $a_{l}$ for the HSC using

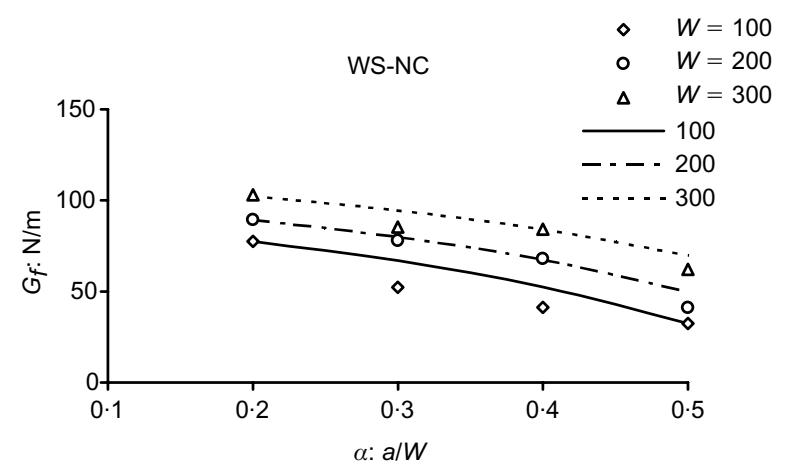

Fig. 10. Comparison of the WS test data for NC for different notch to depth ratios with equation (7)

Magazine of Concrete Research, 2003, 55, No. 2 


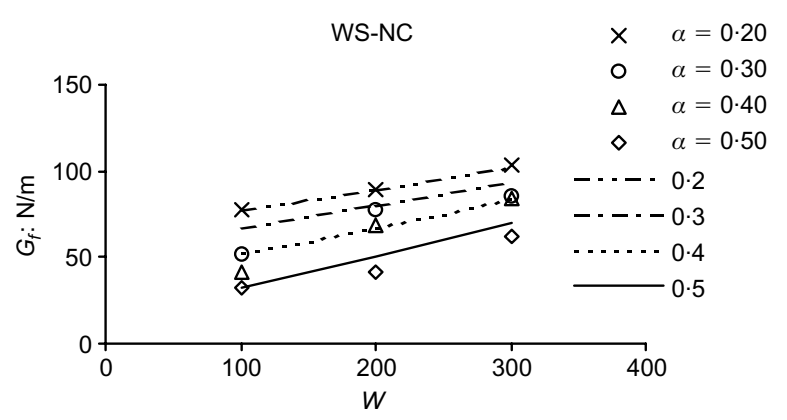

Fig. 11. Comparison of the WS test data for NC for different specimen depths $W$ with equation (7)

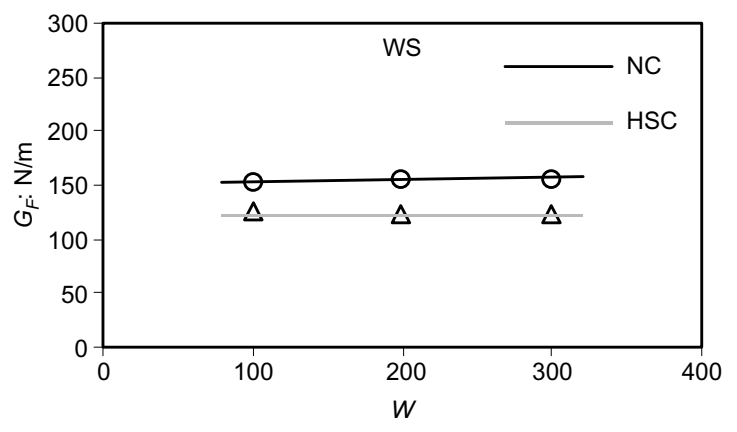

Fig. 12. The size-independent fracture energy $G_{F}$ for $N C$ and $H S C$ as a function of $W$, predicted by equation (7)

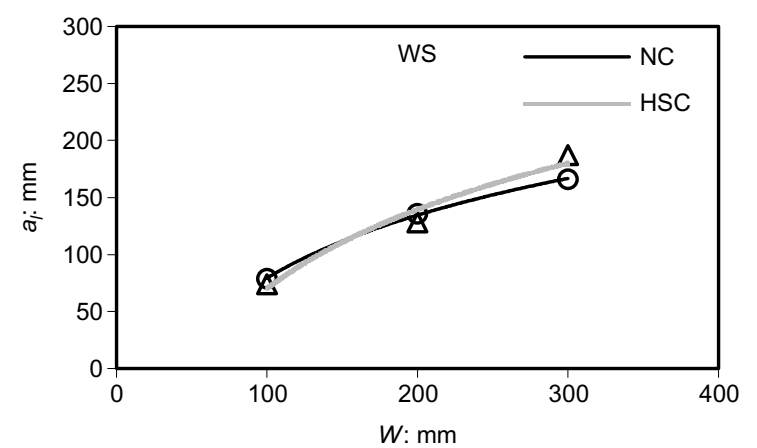

Fig. 13. The transition ligament $a_{l}$ as a function of $W$ for $N C$ and HSC, predicted by equation (7)

equation (7) are shown in Table 5. Fig. 12 again shows that the specific fracture energy $G_{F}$ remains constant for the three different specimen sizes investigated here. The ligament transition length $a_{l}$ for HSC shows the same trend as before, i.e. it increases with the specimen size but at a gradually reduced rate (Fig. 13). The influence of specimen size on the transition ligament length

Table 5. Estimated specific fracture energy $G_{F}$ and ligament transition length $a_{l}$ for HSC using WS test

\begin{tabular}{l|r|r|l}
\hline$W: \mathrm{mm}$ & 100 & 200 & 300 \\
$G_{F}: \mathrm{N} / \mathrm{m}$ & 125 & 122 & 123 \\
$a_{l}: \mathrm{mm}$ & 74 & 128 & 187 \\
\hline
\end{tabular}

$a_{l}$ in fact reflects the influence of the specimen size on the fracture process zone (FPZ). The trend observed in Figs 9 and 13 points to the possibility that the ligament transition length will reach a plateau when the specimen size is very large. Moreover, it seems to be less sensitive to the mix compressive strength.

Figure 14 shows a comparison of equation (7) with the measured fracture energy $G_{f}(\alpha)$ for HSC using the specific fracture energy $G_{F}$ and the ligament transition length $a_{l}$ shown in Table 5. Fig. 15 shows the variation of the specific fracture energy with the specimen depth for the HSC studied here.

\section{Discussion}

The results in Tables 1 and 2 show that the measured fracture energy $G_{f}(\alpha)$ of the NC and HSC studied here are dependent on both the $a / W$ ratio and the specimen size. However, when the model based on the proportionality of the local fracture energy to the FPZ width is applied to $G_{f}(\alpha)$, a specific fracture energy $G_{F}$ is obtained which is independent of both $a / W$ and specimen size. The transition ligament length $a_{l}$ introduced by this model plays an important role in this evaluation. For the TPB test reported here the best results of the size-independent fracture energy $G_{F}$ are obtained when four notch to depth ratios between 0.05 and 0.5 are

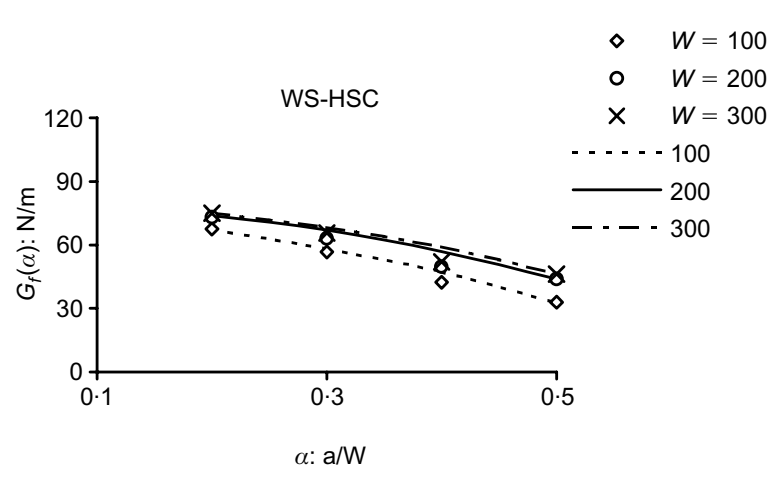

Fig. 14. Comparison of the WS test data for HSC for different notch to depth ratios with equation (7)

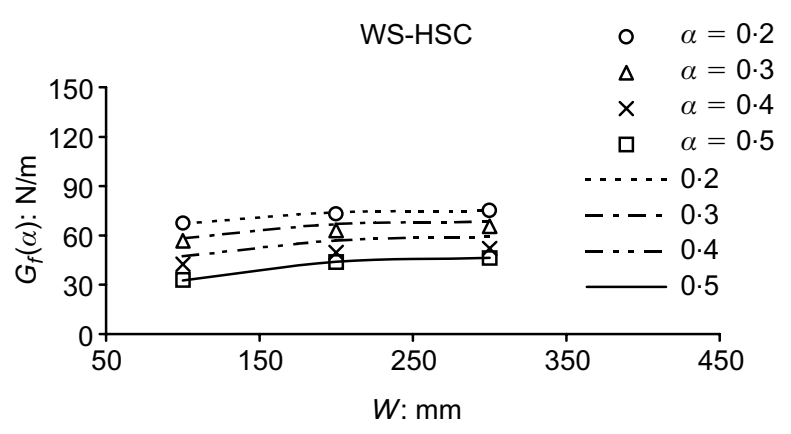

Fig. 15. Comparison of the WS test data for HSC for different specimen depths $W$ with equation (7) 
chosen. However, the same asymptotic value of $G_{F}$ is also obtained from a single size specimen with only two notch to depth ratios, provided they are well separated e.g. $0 \cdot 05$ and 0.5 as shown in Table 6 . If the notch to depth ratios are not well apart, then the value of $G_{F}$ can be very different from the true asymptotic one, as illustrated by the entries in Table 6 .

For the WS test reported here the best results of the size-independent fracture energy $G_{F}$ are also obtained when four notch to depth ratios between 0.2 and 0.5 are chosen. However, as with the TPB test, the same asymptotic value of $G_{F}$ is also obtained from a single specimen size with only two notch to depth ratios, provided they are well separated, e.g. $0 \cdot 2$ and $0 \cdot 5$ (see Table 6).

When using a single size specimen with only two notch to depth ratios it is important that the ratios are well separated. For example, in WS specimens these should be $0 \cdot 2$ and $0 \cdot 5$, but not $0 \cdot 2$ and $0 \cdot 3$ or $0 \cdot 2$ and $0 \cdot 4$ (Table 6). Likewise, in TPB specimens these should be 0.05 and 0.5 , but not 0.05 and $0 \cdot 1$ or $0 \cdot 1$ and $0 \cdot 3$. On the other hand, a single size specimen with three notch to depth ratios which do not cover a wide range (i.e. from 0.05 to 0.5 for TPB) predicts values of $G_{F}$ that show no definite trend towards the asymptotic value (Table 7). Such test specimens should thus be avoided.

\section{Conclusion}

The size effect in the specific fracture energy $G_{F}$ of concrete has been explained in terms of the concept of the local fracture energy and the boundary effect induced by the back surface of a notched test specimen. The latter is felt over a certain distance from the free

Table 6. The specific fracture energy $G_{F}$, obtained from single specimen size and two notch to depth ratios, compared with $G_{F}$ obtained using all specimen sizes and notch to depth ratios (last column)

\begin{tabular}{|c|c|c|c|c|c|c|}
\hline Test & Type of concrete & $W: \mathrm{mm}$ & \multicolumn{4}{|c|}{$G_{F} \mathrm{~N} / \mathrm{m}$} \\
\hline & $\alpha$ & & $0.05,0.1$ & $0.1,0.3$ & $0.05,0.5$ & $0.05,0.1,0.3,0.5$ \\
\hline ТPB & $\mathrm{NC}: 55 \mathrm{MPa}$ & $\begin{array}{l}100 \\
200 \\
300 \\
400\end{array}$ & $\begin{array}{l}320 \cdot 6 \\
249 \cdot 0 \\
253 \cdot 0 \\
223 \cdot 0\end{array}$ & $\begin{array}{l}112 \cdot 0 \\
134 \cdot 4 \\
110 \cdot 2 \\
124 \cdot 3\end{array}$ & $\begin{array}{c}144 \cdot 1 \\
144 \cdot 7 \\
- \\
-\end{array}$ & $\begin{array}{l}140 \cdot 0 \\
144 \cdot 5 \\
137 \cdot 0 \\
143 \cdot 0\end{array}$ \\
\hline \multirow{3}{*}{ WS } & $\alpha$ & & $0 \cdot 2,0 \cdot 3$ & $0 \cdot 2,0 \cdot 4$ & $0 \cdot 2,0 \cdot 5$ & $0 \cdot 2,0 \cdot 3,0 \cdot 4,0 \cdot 5$ \\
\hline & $\mathrm{NC}: 60 \mathrm{MPa}$ & $\begin{array}{l}100 \\
200 \\
300\end{array}$ & $\begin{array}{l}254 \cdot 7 \\
168 \cdot 5 \\
225 \cdot 5\end{array}$ & $\begin{array}{l}186 \cdot 2 \\
153 \cdot 6 \\
159 \cdot 4\end{array}$ & $\begin{array}{l}153 \cdot 0 \\
153 \cdot 7 \\
155 \cdot 4\end{array}$ & $\begin{array}{l}153 \cdot 0 \\
155 \cdot 0 \\
156 \cdot 3\end{array}$ \\
\hline & HSC: $100 \mathrm{MPa}$ & $\begin{array}{l}100 \\
200 \\
300\end{array}$ & $\begin{array}{l}143 \cdot 0 \\
142 \cdot 8 \\
141 \cdot 0\end{array}$ & $\begin{array}{l}143 \cdot 0 \\
143 \cdot 6 \\
144 \cdot 0\end{array}$ & $\begin{array}{l}125 \cdot 2 \\
121 \cdot 9 \\
122 \cdot 8\end{array}$ & $\begin{array}{l}125 \cdot 0 \\
122 \cdot 0 \\
123 \cdot 0\end{array}$ \\
\hline
\end{tabular}

Table 7. The specific fracture energy $G_{F}$, obtained from single specimen size and three notch to depth ratios, compared with $G_{F}$ obtained using all specimen sizes and notch to depth ratios (last column)

\begin{tabular}{|c|c|c|c|c|c|}
\hline Test & Type of concrete & $W: \mathrm{mm}$ & \multicolumn{3}{|c|}{$G_{F} \mathrm{~N} / \mathrm{m}$} \\
\hline \multirow[b]{2}{*}{ ТРВ } & $\alpha$ & & $0 \cdot 1,0 \cdot 3,0 \cdot 5$ & $0 \cdot 05,0 \cdot 1,0 \cdot 3$ & $0 \cdot 05,0 \cdot 1,0 \cdot 3,0 \cdot 5$ \\
\hline & NC: $55 \mathrm{MPa}$ & $\begin{array}{l}100 \\
200 \\
300 \\
400\end{array}$ & $\begin{array}{c}124 \cdot 0 \\
131 \cdot 1 \\
- \\
-\end{array}$ & $\begin{array}{l}154 \cdot 2 \\
158 \cdot 8 \\
137 \cdot 0 \\
143 \cdot 0\end{array}$ & $\begin{array}{l}140 \cdot 0 \\
144 \cdot 5 \\
137 \cdot 0 \\
143 \cdot 0\end{array}$ \\
\hline \multirow{3}{*}{ WS } & $\alpha$ & & $0 \cdot 3,0 \cdot 4,0 \cdot 5$ & $0 \cdot 2,0 \cdot 3,0 \cdot 4$ & $0 \cdot 2,0 \cdot 3,0 \cdot 4,0 \cdot 5$ \\
\hline & NC: $60 \mathrm{MPa}$ & $\begin{array}{l}100 \\
200 \\
300\end{array}$ & $\begin{array}{l}118 \cdot 0 \\
170 \cdot 4 \\
194 \cdot 8\end{array}$ & $\begin{array}{l}186 \cdot 2 \\
153 \cdot 6 \\
159 \cdot 4\end{array}$ & $\begin{array}{l}153 \cdot 0 \\
155 \cdot 0 \\
156 \cdot 3\end{array}$ \\
\hline & HSC: $100 \mathrm{MPa}$ & $\begin{array}{l}100 \\
200 \\
300\end{array}$ & $\begin{array}{l}116 \cdot 2 \\
111 \cdot 4 \\
113 \cdot 9\end{array}$ & $\begin{array}{l}142 \cdot 8 \\
144 \cdot 1 \\
147 \cdot 2\end{array}$ & $\begin{array}{l}125 \cdot 0 \\
122 \cdot 0 \\
123 \cdot 0\end{array}$ \\
\hline
\end{tabular}


back surface, called the ligament transition length $a_{l}$. The size or ligament effect on the specific fracture energy can be explained by the variation of $a_{l}$ with the specimen size. The trend observed from the tests reported here indicates that the transition length increases with the specimen size at a gradually reducing rate, so that it is expected that this length will reach a constant value when the specimen is very large. It is however not very sensitive to the compressive strength of the concrete mix.

The present study has confirmed that testing of very large concrete specimens is not necessary, because $G_{F}$ can be worked out from the measured size-dependent fracture energy $G_{f}(a / W)$, as long as $(W-a)>a_{l}$.

For both the TPB and WS tests, the size-independent fracture energy $G_{F}$ was estimated from three or four specimen sizes with four notch to depth ratios. However, it was demonstrated that the same asymptotic value of $G_{F}$ could also be obtained by testing a single size specimen with only two notch to depth ratios provided they are well separated, i. e. one specimen contains a shallow notch (say $a / W=0.05$ in TPB or $0 \cdot 2$ in WS) and a second specimen of the same size contains a deep notch (say, $a / W=0 \cdot 5$ ). This important observation can greatly simplify the determination of the size-independent $G_{F}$ of concrete. It is now only necessary to obtain $G_{f}(\alpha)$ for two values of $\alpha$ and to use equation (7) to determine $G_{F}$ and $a_{l}$ uniquely without the need for a least squares method of solution.

\section{References}

1. Karihaloo B. L. Fracture Mechanics and Structural Concrete, Addison Wesley Longman, London, 1995.

2. Guinea G. V., Planas J. and Elices M. Measurement of the fracture energy using three-point bend tests: part 1-Influence of experimental procedures. Materials and Structures, 1992, 25, 212-218.

3. Elices M., Guinea G. V. and Planas J. Measurement of the fracture energy using three-point bend tests: part 3-Influence of cutting the $P-\delta$ tail. Materials and Structures, 1992, 25, 327-334.

4. HU X. Z. and WittmanN F. H. Fracture energy and fracture process zone. Materials and Structures, 1992, 25, 319-326.

5. DuAn K., HU X. Z. and Wittmann F. H. Boundary effect on concrete fracture induced by non-constant fracture energy distribution, in Fracture Mechanics of Concrete Structures (R. De Borst, J. Mazars, G. Pijaudier-Cabot and J. G. M. Van Mier (Eds)), Proc. FRAMCOS-4, 49-55. A. A. Balkema Publishers, Rotterdam, 2001.

6. RILEM COMMITTEE FMC 50. Determination of the fracture energy of mortar and concrete by means of the three-point bend tests on notched beams. Materials and Structures, 1985, 18, 285-290.

7. Hillerborg A. Analysis of one single crack, in Fracture Mechanics of Concrete (F. H. Wittmann (Ed)), Elsevier, Amsterdam, 1983, 223-249.

8. Hillerborg A. The theoretical basis of a method to determine the fracture energy $G_{\mathrm{F}}$ of concrete. Materials and Structures, 1985, 18, 291-296.

9. HU X. Z. Fracture process zone and strain softening in cementitious materials. ETH Building Materials Report No.1, ETH, Switzerland, AEDIFICATIO, Freiburg, 1995.

10. HU X. Z. and WitTMANN F. H. Size effect on toughness induced by crack close to free surface. Engineering Fracture Mechanics, 2000, 65, 209-211.

11. Nallathambi P., Karihaloo B. L. and Heaton B. S. Effect of specimen and crack size, water/cement ratio and coarse aggregate texture upon fracture toughness of concrete. Magazine of Concrete Research, 1984, 36, 227-236.

12. Nallathambi P., Karihaloo B. L. and Heaton B. S. Various size effects in fracture of concrete. Cement and Concrete Research, 1985, 15, 117-121.

Discussion contributions on this paper should reach the editor by 1 October 2003 